\title{
Through a computational lens: using dual computer-criminology degree programs to advance the study of criminology and criminal justice practice
}

\author{
Colby L Valentine ${ }^{1 *}$, Carter Hay ${ }^{2}$, Kevin M Beaver ${ }^{2}$ and Thomas G Blomberg ${ }^{2}$
}

\begin{abstract}
Computational criminology seeks to address criminological and criminal justice problems through the use of applied mathematics, computer science, and criminology. The development of mathematical and computational methods along with the emergence of cyberspace demonstrates the need for innovative degree programs that focus on computational criminology. The purpose of this article is to highlight the significance of dual computer-criminology degree programs. The article first discuses two major shifts in the study of criminology: the facilitation of new methodologies and data techniques; and, the development of new types of crime and delinquency through advancements in computer technology. Next, the article describes the need for dual computer-criminology degree programs and employs Florida State University's program as an example of what these programs offer aspiring criminologists. Finally, the article concludes with discussion of future plans for the Florida State University dual computer-criminology degree program that are applicable to other criminology programs both within the United States and also internationally.
\end{abstract}

Keywords: Computer criminology, Degree program, Cyber crime, Florida State University

\section{Introduction}

Beginning Fall 2007, Florida State University (FSU) offered an interdisciplinary undergraduate degree program in Computer Criminology and in Fall 2011, FSU began offering students the opportunity to pursue a Master's of Science in Computer Criminology. The FSU Department of Computer Science and the College of Criminology and Criminal Justice jointly developed these new degree programs in response to the technological and computational shifts that have emerged in the field of criminology and criminal justice. Specifically, these degree programs relate to the specialization of computational criminology, which seeks to address criminological problems through the use of applied mathematics, computer science, and criminology. Degrees that focus on mathematical and computation science are crucial to

\footnotetext{
* Correspondence: colby.valentine@dc.edu

'Dominican College, 470 Western Highway, Orangeburg, New York 10962, USA

Full list of author information is available at the end of the article
}

prepare new students and future scholars for the changing subject matter in the field as research is advancing and new areas of focus are unraveling every day as well as preparing criminal justice practitioners in their efforts to effectively confront the emerging cyber aspects of crime.

Computational criminology is an emerging field that has developed primarily from two areas over the past 30 years. First, the development of crime simulation models and related computer methodologies has emerged as a new way to study crime. Computational criminology has been pioneered in the field of environmental criminology. Liu and Eck (2008) describe artificial crime analyses and simulation as methods to reveal hidden processes of urban crimes by combining criminology, computer simulation, and geographic information systems [1]. Two other prominent researchers in this area, Patricia and Paul Brantingham, have focused their research on environmental or contextual factors that can influence criminal activity. Their research initiated the development of the Computational Criminology Initiative (CCI), which 
allows for new visualization techniques for understanding crime patterns.

Another area of computational criminology that has emerged in criminological and computer science research is the development of computer crimes and related criminal activity in cyberspace [2]. However, the development of research in computer and cyber crime within the field of criminology has just begun to develop over the past few years. The first conference devoted to cyber and computer criminology was the "Cyber Criminology and Digital Forensics Initiative Conference" which was held in Spokane Valley, Washington in October 2006. Then in 2007, the International Journal of Cyber Criminology (IJCC) began publication as a peer reviewed online (open access) interdisciplinary journal dedicated to the study of cyber crime, cyber criminal behavior, cyber victims, cyber laws, and cyber investigations [3].

The development of mathematical and computational methods along with the emergence of cyberspace as a new locus for criminal activity demonstrates the need for innovative degree programs that focus on computational criminology. The two purposes of this article are: first, to describe from a criminological perspective the technological and computational shift in the study of criminology and criminal justice, and second, to highlight how dual computer-criminology degree programs advance the study of crime in ways that address needs for both researchers and practitioners in the field of criminal justice.

The article begins with a discussion of two major shifts in the study of criminology: the facilitation of new methodologies and data techniques; and, the development of new types of crime and delinquency through advancements in computer technology. Next, the article describes the need for dual computercriminology degree programs and employs FSU's program as an example of what these programs offer aspiring criminologists. Finally, the article concludes with discussion of future plans for the FSU dual computer-criminology degree program that are applicable to other criminology programs.

\section{The technological shift in the study of criminology and criminal justice}

Computational criminology is an emerging field that is generating new and innovative methodologies. These include new criminological models, calculated algorithms, spatial and temporal dynamics of crime and terrorism, co-offending network analysis, data structures and software development, and the mining of crime, offender and criminal justice systems data. For example, advancements in computational power and the availability of new data have allowed new types of methodologies to evolve within the study of criminology. Brantingham and colleagues (2009) describes one niche computational criminology addresses regarding crime analyses and data for studying crime patterns:

The recent emergence of computational criminology, grounded on improvement in the computational power available to researchers, provides, potentially, a way to link theory and research at a micro level with theory and reassert at the meso levels of analysis (p.90).

The authors further expand on this concept by presenting an algorithm based on analysis of land unit to unit similarity to demonstrate how crimes patterns develop in and around certain neighborhoods [4]. The findings offer an innovated data technique that may aid in the computational expansion of crime pattern research that can guide more effective geographic targeting of crime control efforts. Additional work pioneered by Brantingham and collegues $(2005 ; 2009)$ demonstrate how mathematical and computational methods, such as those based on the abstract state machine (ASM) paradigm, allow for the modeling and simulation of crime patterns. These methods aim to advance criminological approaches toward crime reduction and prevention. For example, some of the purposes of mathematical computation models include helping predict the likelihood of criminal activity occurring in certain places, creating scenarios in crime analysis and simulating prevention techniques to provide a basis for experimental research that is difficult to produce in real-work settings, and designing critical infrastructure protection $[5,6]$.

Artificial crime analysis and crime simulation is an emerging area that highlights the advancement in computation criminology. Liu and Eck's (2008) edited book that addresses a number of issues relating to crime analyses using computer simulations and geographical information systems. Their book is focused around four sections exploring such topics as using simulation to understand crime patterns and criminal justice processes, an analysis of conditions that might influence crime patterns, crime event and pattern simulation, and criminal justice operation simulations. Several chapters provide examples that demonstrate how simulations are used as a tool to understand crime patterns [1]. The book also summarizes four purposes of artificial crime analysis: theorizing, estimating, testing, and planning [7].

Some of the research on crime analysis and simulation specifically illustrate the purposes for using crime simulations. For instance, agent-based models for crime simulations can be particularly useful for theorizing. Specifically, spatial adaptive crime event simulations (SPACES) can be used to explore theory. Theoretical experiments or scenarios can determine how elements of a theory work together and whether the theory can help produce crime patterns. If so, then SPACES may be 
able to produce hypotheses that can be tested using empirical data [8]. Further, simulations can be implemented to test policies. Szakas, Trefftz, Ramirez, and Jefferis (2008) use simulations to test various police patrols methods. These methods, for example, can assist with geographical profiles of suspects or parolees at home and/or at work [9]. Simulations can also be used in predicting and understanding the effect of changes within the criminal justice system [10]. These examples demonstrate how advancements in computation and simulation models yield new methods and techniques, which can advance insights on a variety of issues relating to crime and justice practices.

The rapid growth in computational simulations in the field of criminology and criminal justice is further demonstrated by research that focuses on a variety of issues and complexities related to applying these mathematical models. The Journal of Experimental Criminology published a special issue relating to simulated experiments in criminology and criminal justice. The special issue focused on simulation models and their contributions to criminology regarding unique techniques used to test intervention practices and model outcomes. For example, Auerhahn (2008) used data-validated dynamic systems simulation modeling to examine the effect of California's Three Strikes law on the state's prison population. The simulation model allowed for a prospective analysis of the future effects of the legislation. Therefore, when evaluating policy, the simulation model has an advantage for criminologists by looking both retrospectively at the legislation and also formulating future effects and foreseeing the consequences of those outcomes [11]. Another innovative study developed an agent-based model to test the effects of three different police strategies (i.e., random patrol, hot-spot policing, and problemorientated policing) on a street-level drug market. The authors simulated a disruption in the heroin supply chain to attempt to better understand the various police interventions [12]. Both of the above computational models illustrate how the use of such methods further develops criminological thought and practice related to providing useful simulations capable of generating comprehensible empirical description from which grounded explanations and predictions can be derived.

Computational methods have the ability to enhance the study of criminology but they also can pose a number of challenges for researchers. Berk (2008) examines the complexities of model validation, specifically degrees of credibility, for computational models and further concludes that simulation models can benefit the development and refinement of theory. However, criminologists must continue to test computer models against data [13]. Further, Townsley and Birks (2008) discuss the need for replication of computational model to enhance their validity [14]. Despite these challenges, simulations have great promise in the field of criminology and are yet another tool for criminologists to use that can complement traditional data-driven methods.

\section{New types of crime and delinquency}

Beyond mathematical and computational methods, the development of cyber and computer crime has also transformed the way criminologists study crime and delinquency. Historically, criminologists have focused on traditional forms of crime (e.g., murder, assaults, kidnapping, etc.); however, during the past few decades, crime has moved to the Internet, opening the door to new types of crime and delinquency, as well as, new methods of engaging in crime. This section briefly describes how the study of criminology has shifted to include the Internet through advancements in technology and the use of computers. Although cyber crime research is relatively new to criminology, this area of research is gaining momentum [15]. As a result, the literature on this topic is extensive and summarizing it is beyond the scope of this article. As a result, we provide only a snapshot of the research, taken from the journal that pioneered the field, to demonstrate this new avenue of research emerging from the development and growth of computer and cyber crime. Thus, the purpose of this section is to clarify the way in which computers have become central to the commission of many categories of crime. Specifically we review and discuss three categories of computer crimes that illustrate this emerging pattern and point to the need to prioritize the intersection of computer science and the traditional study of criminology and criminal justice.

Cyber and computer crime have emerged as new areas of research for criminologists and in doing so have provided new opportunities to apply theory to help explain such crime. Crimes that are associated with the prevalence of computers target the technological industry, its customers, and others [16]. Some of the crimes that are incorporated into this category include counterfeiting, identity theft, corporate theft, component theft, and piracy. Digital piracy is the act of copying digital goods (i.e., software, documents, audio, and video) without permission from and compensation to the copyright holder using computer technology [17-19]. Digital piracy is one area of research that has emerged within cyber criminology and covers topics such as music, gaming, and other computer programs.

Empirical research on piracy has focused on some of the correlates that may be associated with digital piracy, in addition to, examining criminological theories in the context of digital piracy. For example, Moore and McMullan (2009) conducted qualitative interviews with university students to determine whether neutralization techniques were employed by file sharers and found that each participant indicated support for at least one 
technique of neutralization in justifying their piracy activities [20]. Also focusing on neutralization theory, Higgins, Wolfe, and Marcum (2008) examined the trajectories of digital piracy among college students and found that the level of neutralization utilized by a potential music pirate affects the piracy that actually occurs [21]. In addition, Higgins (2007) examined other criminological theories, self-control and rational choice, to explain digital piracy and found that low self-control and situational factors had direct and indirect effects with intentions to engage in digital piracy [22].

The above research demonstrates how the merging of computer technology and criminology has created a new research area for scholars. Advancements in technology have created new types of crime, such as digital piracy, for researchers to examine using criminological theories. In addition, a computational understanding of piracy can give scholars a unique understanding of the crime. Dual computer-criminology degree programs, thus, facilitate the merging of two disciplines that can aid future research on piracy and other computer related crimes and, also, aid in the prevention and control of further illegal digital transmissions.

Other forms of cyber crimes, that use the computer as an instrument of the crime or are incidental to the crime, have illustrated the shift in crimes from society to cyberspace. For example, crimes that use the computer as an instrument of the crime include offenses when the computer is used to gain something. Therefore, the criminal uses the computer or the network to perform crimes such as theft, fraud, exploitation, threats, or harassment [16]. Cyber bulling and cyber stalking has become a hot topic among schools, parents, the media, political forums and, more recently, among criminologists. The empirical research on cyber bullying is extensive and reveals the high prevalence among adolescents of internet-based harassment that includes abusive e-mails, insulting messages or pictures posted on online message boards, and Web-sites that disseminate disparaging information about an individual [23-25]. One special concern about cyber bullying is its potentially relentless nature. Because many adolescents-for legitimate reasons-frequently use the Internet, they can be exposed to cyber bullying even when physically removed from bullies. Thus, as Mason (2008:324) notes, with cyber bullying, "home may no longer be a place of refuge" [26]. With these issues in mind, cyber bullying has attracted significantly attention in many disciplines, and the International Journal of Cyber Criminology has published numerous articles on this topic, which include an international study of bullying in web forums [27], an examination of polices and legal obligations associated with cyber bullying [28], and the effectiveness of cyber bullying prevention strategies [29].
Compared to cyber bullying, less research has been conducted on cyber stalking. Pitarro (2007) conducted an analysis on cyber stalking and examined the deviant behaviors and tactics associated with cyber stalking crimes, legislative intervention measures, and preventative initiatives [30]. Another descriptive article appeared in the International Journal of Cyber Criminology providing an overview of the current state of knowledge on cyberstalking and examined the difficulties in investigating and prosecuting cyber-stalkers. Roberts (2008:281) concludes her article by arguing for the "...continued training of law enforcement and legal officers to increase their technological sophistication and understanding of cyber-stalking behaviours" [31]. A dual computer-criminology degree tackles both the understanding and technological elements of this crime.

Prior research on cyber bullying and cyber stalking, demonstrate how specific types of crimes have evolved through advancements in the Internet; thereby, providing new ways to engage in deviant behaviors. Cyber bullying, threats, harassment, and stalking have developed as new research areas focusing on the way some individuals misuse technology. Consequently, the increasing prevalence of this type of crime should be further integrated into the study of criminology and dual computer-criminology degree program are a necessary medium to advance such research and subsequently guide polices aimed at preventing and reducing these particular crimes.

Further, crimes that focus on computers as a target exemplify the need for an understanding in computation technology and mathematical methodologies to employ effective investigation and prevention strategies. For example, crimes that focus on the computer as a target include such acts as, denying the user or owner access to their computer or data, alteration of data on the computer, network intruding, and computer vandalism [16]. A common example of such a crime is hacking. Hacking is commonly described as "act of re-designing the configuration of hardware or software systems to alter their intended function" [32]. Bachmann (2010) examined the risk propensity and rationality of computer hackers. The author used a number of criminological theories to explain the findings of the study including rational choice, self-control, and, related specifically to cyber crime, space transition theory [32]. This type of computer related deviance is an example of how criminologists can benefit from individuals with an educational background in both criminology and computer science. Scholars with a degree in computer criminology have an understanding of how computers facilitate the study of crime and how crimes are accomplished through the use of computers. Further, to aid in the prevention and intervention of such crimes, individuals need to understand the methods of such crimes and the elements of computer systems that an 
education in computer criminology can provide through the teaching of criminological research, theory, computer systems, and procedures.

\section{Dual computer-criminology degree programs}

Given these developments in computational models, computer technology, and cyber crime, it is not surprising that there is a growing recognition of the need and usefulness of studying crime at the computational level through dual computer-criminology degree programs. Computer criminology is a relatively new field, and departments are beginning to add computer criminology as a major for current and incoming students. In particular, the FSU dual computer-criminology degree program presents what could become a standard in the future to keep up with the rapidly growing areas of cybercrime and its control. The FSU program focuses on areas such as information-related crime, cyber-forensics, and computer/network security. Computer criminology includes both how to use computers to facilitate the study of crime and the study of how crimes are accomplished through the use of computers. Students graduating from FSU will be prepared to do graduate work and research in this area, or have the opportunity to become effective employees of government, law enforcement, or other related public and private agencies.

FSU's dual computer-criminology degree program is presented as a case example to illustrate how a computer criminology degree can prepare students for future graduate work and/or employment. To this end, the next section provides examples of courses from both criminology and computer sciences that are available to students at both the undergraduate and graduate level.

\section{Undergraduate degree program}

In 2007, Florida State University first offered an undergraduate degree program in computer criminology for current and incoming students. The degree program is a four-year program that focuses on a combination of general education requirements based on University standards, computer science courses, and criminology courses. Students may elect to pursue the major by either graduating through the Department of Computer Sciences within the College of Arts and Sciences or through the College of Criminology and Criminal Justice. One of the key hallmarks of the program is the close connection between the computer science program and the criminology program. In short, students pursuing a degree in computer criminology get the "best of both worlds" by learning from world-class researchers in computer science as well as world-class researchers in criminology.

Students majoring in computer criminology are required to take courses that focus on computer science, criminology, and mathematics. Some of the required courses for computer science include courses that focus on the fundamentals of computer organization, computer operating systems, and computer programming. The capstone course offered in the computer science department for the major is cybercrime detection and forensics. The courses focus on learning tools, techniques, and procedures for detecting cybercrime and analyzing collected data related to past and ongoing cybercrime offenses. The course also concentrates on forensic approaches that preserve the legal value of the collected evidence.

In addition to the required computer science courses, students are also required to complete a number of criminology courses. The criminology curriculum includes courses that focus on criminological theories, crime investigation techniques, and research methodologies in criminology. The capstone course offered in the criminology department for the major is criminal justice system responses to cybercrime. This course explores the various types of criminal conduct associated with computers and the World Wide Web. Additionally, it covers digital forensics, theories of digital crime and terrorism, and policy implications and laws related to cybercrime. Furthermore, the criminology capstone course covers in detail the prominent forms of computer crime and the legal issues that emerge in confronting those crimes. That class has been organized in part around Taylor et al.'s (2011) Digital Crime and Digital Terrorism, and one appealing feature of that text is its attention to the global and international nature of much computer crime [16]. Many computer crimes involve actions that cross international boundaries and this text meticulously describes the legal issues that surround both computer and cyber crimes. For example, the text dedicates an entire section to controlling digital crime through legislation, law enforcement, and investigation.

Further, students can choose to take additional courses, in both majors, to focus their studies to their personal interests within the field. In computer science, some the courses focus on issues related specifically to computer structures such as ethical aspects of computer security, fundamental theories in computer security, and computer operating systems. Within criminology and criminal justice, some of the specialized courses concentrate on the criminal justice system, theories of criminal justice, the court system, corrections, and law enforcement. The wide range of courses offered by both programs allows the student to focus on their particular interests within the field of computation criminology. Students are also required to complete a mathematics course, which is offered by the Department of Mathematics in the College of Arts and Sciences. The purpose of the course is to develop knowledge and skills in fundamental mathematics' topics that are relevant to the computer specialization part of the degree, particularly to the systematic development of software. 
Students obtaining a bachelor's degree in computer criminology are also given the opportunity to complete an internship before graduation. This internship, if the student decides to enroll in the course, can provide the student with work experience that will help in obtaining a job after graduation.

\section{Graduate degree program}

In 2011, FSU extended the undergraduate degree program with the addition of a graduate degree in computer criminology. Students pursuing a Masters of Science in computer criminology are admitted to and graduate from the Department of Computer Science; however, the graduate degree focuses on courses from both criminology and computer sciences. The degree program is a coursework-only track and provides a large number of courses at the graduate level. For example, courses in criminology cover topics such as crimes of the powerful, theoretical issues and research on the law and legal control of deviance in society, criminological theory, historical reviews of thought about crime and punishment, and comparative criminology and criminal justice. In addition, a variety of computer sciences courses are also offered and include topics such as computer security, network security, active, and passive defenses, data and computer communications, computer and network administration, advanced operating systems, and database systems.

\section{Employment and research opportunities}

Computer crime, as previously described, can be broadly defined as any criminal activity that involves the use of information technology, including illegally accessing information, intercepting data, damaging or deleting data, interfering with the functioning of a computer system, identity theft, etc. Information-related crime and computer/ network security issues are already major concerns. These issues affect all levels of business, government, and academia and have grown in importance as most organizations link their networked computer environments to the Internet. A computer criminology student will learn both how to use computers to facilitate the study of crime and will study how crimes are accomplished through the use of computers.

Based on current trends, we anticipate there will be a significant demand for graduates of both the undergraduate and graduate computer criminology program. It is well known that there is a shortage of information technology experts. Similarly, there is a pressing need for information technology specialists to handle issues related to information crime, cyber-forensics, and computer/ network security. However, there is also a need for computer skills for the prevention, detection, and study of all types of crime, whether or not they involve the use of information technology. Graduates of the program will be prepared to work either for law enforcement agencies as information crime specialists, within companies or organizations as network security specialists, or within academia and government to study the causes of crime and the best methods for its prevention and control.

\section{Conclusion}

The purpose of this article was to describe the technological and computational shifts in the study of criminology and criminal justice as well as highlight the significances of dual computer-criminology degree programs. The FSU program description was used to provide an example of an ongoing dual computercriminology program at both the undergraduate and graduate level. It is anticipated that some of the master's students in computer-criminology will decide to continue their studies for a Ph.D., given the growing discipline and policy importance of cyber-crime. FSU is currently involved in discussions on the structure, content, and requirements for a Ph.D. in computer criminology. The expansion of the program would push for the advancement of research that informs public policy. For instance, compared to a master's degree that trains students to be informed, knowledgeable users of scientific research, the Ph.D. prepares students to conduct their own original research to generate new insights on issues of scientific and public policy importance. This necessarily emphasizes comprehensive training in theory, research methods, and statistics that would be specific to the study of cyber-crime. Thus, the goal of a Ph.D. program in computer criminology would be to produce Ph.D. graduates who could generate the new research needed to inform policymakers and the scientific community on the causes and consequences of cyber crime and the appropriate legal and extra-legal responses to it. In addition to the Ph.D. program, FSU is also currently involved is discussions on including the dual computercriminology degree program with the FSU distance learning program to expand the number of students who are able to learn from the best researchers and instructors in the fields of criminology and computer science. The anticipated implementation of both the Ph.D. program and the online program will continue to enhance the computer-criminology degree program and further benefit the expanding field of computational criminology.

\section{Competing interests}

The authors declare that they have no competing interests.

\section{Authors' contributions}

CV made substantial contributions to the conception and design of the article, drafted the manuscript, and formatted the manuscript. $\mathrm{CH}$ provided information about the degree programs, offered important intellectual 
content, revised earlier drafts, and offered suggestions on earlier drafts. KB provided information about the degree programs, revised earlier drafts, and offered important intellectual content. TB revised earlier drafts and offered important intellectual content. All authors read and approved the final manuscript. All authors reviewed and made edits to the revised manuscript.

\section{Authors' information}

Colby Valentine, $\mathrm{PhD}$, is an assistant professor of Criminal Justice in the Social Sciences Division of Dominican College. Her current research focuses on inmate misconduct, officer-involved domestic violence, and neighborhood predictors of intimate partner violence. She has recent publications in Journal of Family Violence, Family Court Review, and Journal of Human Behavior in the Social Environment.

Carter Hay, PhD, is an associate professor in the College of Criminology and Criminal Justice at Florida State University. His research examines the causes and prevention of individual involvement in crime and delinquency, with recent or forthcoming publications appearing in such journals as Crime \& Delinquency and Youth Violence and Juvenile Justice.

Kevin M. Beaver, PhD, is an associate professor in the College of Criminology and Criminal Justice at Florida State University. He is past recipient of the American Society of Criminology's Ruth Shone Cavan Young Scholar Award and his research focuses on the genetic and biosocial foundations to antisocial behaviors. His research has produced more than 150 articles and book chapters which appear in a variety of interdisciplinary publication outlets.

Thomas G. Blomberg is Dean and Sheldon L. Messinger Professor of Criminology at Florida State University's College of Criminology and Criminal Justice and Editor of Criminology and Public Policy. He had published extensively in the areas of penology, social control, and education and recidivism. His recent books include Punishment and Social Control: Enlarged Second Edition (2003) and American Penology: Enlarged Second Edition (2010)

\section{Author details}

'Dominican College, 470 Western Highway, Orangeburg, New York 10962, USA. ${ }^{2}$ Florida State University, College of Criminology and Criminal Justice, 634 W. Call Street, Tallahassee, Florida 32306-1127, USA.

\section{Received: 11 January 2012 Accepted: 27 December 2012} Published: 16 January 2013

\section{References}

1. L Liu, J Eck, An overview of crime simulation, in Artificial crime analysis systems: using computer simulations and geographical information systems, ed. by L Liu, J Eck (Information Science References, Hersey PA, 2008), pp. xiv-xxi

2. D Thomas, B Loader, Introduction - cyber crime: law enforcement, security and surveillance in the information age, in Cyber crime: Law enforcement, security and surveillance in the information Age, ed. by D Thomas, B Loader (Routledge, London, 2000), pp. 1-13

3. K Jaishankar, Cyber criminology: evolving a novel discipline with a new journal. Int. J. Cyber. Criminol. 1, 1-6 (2007)

4. PL Brantingham, PJ Brantingham, M Vajihollahi, K Wuschke, Crime analysis at multiple scales of aggregation: a topological approach, in Putting crime in its place: units of analysis in geographic criminology, ed. by D Weisburg, W Bernasco, GJN Bruinsma (Springer, New York, 2009), pp. 87-107

5. PL Brantingham, U Glasser, B Kinney, K Singh, M Vajihollahi, A computational model for simulating spatial aspects of crime in urban environments, in Proceedings of the 2005 IEEE international conference on systems, Man and cybernetics, ed. by M Jamshidi, 2005, pp. 3667-3674

6. PL Brantingham, U Glasser, P Jackson, M Vajihollahi, Modeling criminal activity in urban landscapes, in Mathematical methods in counterterrorism, ed. by N Memon (Springer, Berlin, 2009), pp. 9-31

7. J Eck, L Liu, Varieties of artificial crime analysis: purpose, structure, and evidence in crime simulations, in Artificial crime analysis systems: using computer simulations and geographical information systems, ed. by L Liu, J Eck (Information Science References, Hersey PA, 2008), pp. 413-432

8. X Wang, L Liu, J Eck, Crime simulation using GIS and artificial intelligent agents, in Artificial crime analysis systems: using computer simulations and geographical information systems, ed. by L Liu, J Eck (Information Science References, Hersey PA, 2008), pp. 209-225

9. J Szakas, C Trefftz, R Ramirez, E Jefferis, Development of an itelligent partol routing system using GIS and computer simulations, in Artificial crime analysis systems: using computer simulations and geographical information systems, ed. by L Liu, J Eck (Information Science References, Hersey PA, 2008), pp. 339-351

10. A Alimadad, P Borwein, P Brantinham, P Brantinham, V Dabbaghian-Abdoly, R Ferguson, E Fowler, AH Ghaseminejad, C Giles, J Li, N Pollard, A Rutherford, A van der Waall, Using varieties of simulation modeling for criminal justice analysis, in Artificial crime analysis systems: using computer simulations and geographical information systems, ed. by L Liu, J Eck (Information Science References, Hersey PA, 2008), pp. 372-409

11. K Auerhahn, Using simulation modeling to evaluate sentencing reform in California: choosing the future. J. Exp. Criminol. 4, 241-266 (2008)

12. A Dray, L Mazerolle, P Perez, A Ritter, Policing Australia's 'heroin drought': using an agent-based model to stimulate alternative outcomes. J. Exp. Criminol. 4, 267-287 (2008)

13. R Berk, How you can tell if the simulations in computational criminology any good. J. Exp. Criminol. 4, 289-308 (2008)

14. M Townsley, DJ Birks, Building better crime simulations: systematic replication and the introduction of incremental complexity. J. Exp. Criminol. 4, 309-333 (2008)

15. K Jaishankar, Cyber criminology: exploring internet crimes and criminal behavior (Taylor and Francis Group, Boca Raton, 2011)

16. RW Taylor, EJ Fritsch, J Liederbach, TJ Holt, Digital crime and digital terrorism, 2nd edn. (Prentice Hall, Upper Saddle River NJ, 2011)

17. RD Gopal, GL Sanders, S Bhattacharjee, M Agrawal, SC Wagner, A behavioral model of digital music piracy. J. Organ. Comput. Electron. Commer. 14, 89-105 (2004)

18. WD Gunter, GE Higgins, RE Gealt, Pirating youth: examining the correlates of digital music piracy among adolescents. Int. J. Cyber. Criminol. 4, 657-671 (2010)

19. GE Higgins, BD Fell, AL Wilson, Digital piracy: assessing the contributions of an integrated self-control theory and social learning theory using structural equation modeling. Criminal. Justice. Studies. 19, 3-22 (2006)

20. R Moore, EC McMullan, Neutralizations and rationalizations of digital piracy: a qualitative analysis of university students. Int. J. Cyber. Criminol. 3, 441-451 (2009)

21. GE Higgins, SE Wolfe, CD Marcum, Music piracy and neutralization: a preliminary trajectory analysis from short-term longitudinal data. Int. J. Cyber. Criminol. 2, 324-336 (2008)

22. GE Higgins, Digital piracy, self-control theory, and rational choice: an examination of the role of value. Int. J. Cyber. Criminol. 1, 33-55 (2007)

23. S. Hinduja, JW Patchin, Bullying beyond the schoolyard: preventing and responding to cyberbullying (Corwin Press, Thousand Oaks CA, 2009)

24. J Wang, RJ lannotti, TR Nansel, School bullying among adolescents in the united states: physical, verbal, relational, and cyber. J. Adolesc. Heal. 45 368-375 (2009)

25. M Ybarra, K Mitchell, Online aggressor/targets, aggressors, and targets: a comparison of associated youth characteristics. J. Child. Psychol. Psychiatry. 45, 1308-1316 (2004)

26. KL Mason, Cyber bullying: a preliminary assessment for school personnel. Psychol. Sch. 45, 323-348 (2008)

27. C Su, TJ Holt, Cyber bulling in Chinese Web forums: an examination of nature and extent. Int. J. Cyber. Criminol. 4, 672-684 (2010)

28. S Shariff, DL Hoff, Cyber bullying: clarifying legal boundaries for school supervision in cyberspace. Int. J. Cyber. Criminol. 1, 76-118 (2007)

29. EM Kraft, J Wang, Effectiveness of cyber bullying prevention strategies: a study on Students' perspectives. Int. J. Cyber. Criminol. 3, 513-535 (2009)

30. ML Pittaro, Cyber stalking: an analysis of online harassment and intimidation. Int. J. Cyber. Criminol. 1, 180-197 (2007)

31. L Roberts, Jurisdictional and definitional concerns with computer-mediated interpersonal crimes: an analysis on cyber stalking. Int. J. Cyber. Criminol. 2, 271-285 (2008)

32. M Bachmann, The risk propensity and rationality of computer hackers. Int. J. Cyber. Criminol. 4, 643-656 (2010)

doi:10.1186/2190-8532-2-2

Cite this article as: Valentine et al:: Through a computational lens: using dual computer-criminology degree programs to advance the study of criminology and criminal justice practice. Security Informatics 2013 2:2. 